\title{
Synthesis of Polydimethylsiloxane-Grafted Fluoropolymers and Properties for Hydrophobic Materials
}

\author{
Hiroshi SuZUKI, Toru KoBAYASHI, and Makoto TAKEISHI ${ }^{\dagger}$ \\ Department of Materials Science and Engineering, Yamagata University, \\ Yonezawa, Yamagata 992-8510, Japan
}

(Received September 29, 1999)

KEY WORDS Fluoropolymer / Polydimethylsiloxane / Grafting / Water Repellent / Coating /

Fluoropolymers, represented by Teflon, are widely used as hydrophobic materials because they have not only water-repellent but also oil-repellent properties due to low surface free energy. Other polymers such as polysiloxanes have been investigated as hydrophobic materials. Fluoropolymers have required mechanical properties polysiloxanes lack and thus are useful as water-repellent materials. Because contact angles of water on their coatings are rather large, water drops on coating surfaces fall down easily when the plane surfaces are tilted. However, a small water droplet of $10 \mu \mathrm{l}$ remains on the coating even when put vertically. This is ascribed to polar interactions between water molecules and highly polarized carbon-fluorine bonds of the fluoropolymers. Although contact angles of water on polysiloxane surfaces are smaller than those on the surfaces of fluoropolymers, a water drop on the former surface slides more easily than on the latter surface. Practical application of polysiloxanes is, however, restricted for lacking required mechanical properties such as hardness. To combine these two hydrophobic materials, polysiloxanes that have fluorinated alkyl chains as pendant or end groups have been synthesized and contact angles of water on their solid surfaces measured, ${ }^{1}$ but sliding of water drops on the surfaces of such materials has not been mentioned. It is rather difficult to combine fluoropolymers with polysiloxanes by chemical reaction because of poor miscibility. Nevertheless, a report on sliding of water drops on surfaces of polymeric materials obtained by combination of a fluoropolymers and a polysiloxane has been published. ${ }^{2}$ We recently synthesized a novel hydrophobic material by grafting a polydimethylsiloxane that has an epoxide end group onto a fluoropolymer possessing hydroxyl side groups using strong acid catalysts and found that small water drops slide easily on the surface of a coating prepared from the graft polymer. ${ }^{3}$ The development of hydrophobic materials that easily release water droplets from their surfaces is expected. In this study we synthesized an isocyanateterminated polydimethylsiloxane and grafted it onto a fluoropolymer having hydroxyl side chains to obtain a hybrid polymer and examined its hydrophobicity by sliding a water droplet on the surface of a coating prepared from the graft polymer.

\footnotetext{
${ }^{\dagger}$ To whom correspondence should be addressed.
}

\section{EXPERIMENTAL}

\section{Materials}

A fluoropolymer having hydroxyl side chains (P1) was supplied by Asahi Grass Co. Ltd., whose chemical structure is shown in Scheme 1: $\bar{M}_{n} 15500$ (GPC), the hydroxyl value $57 \mathrm{mgKOH} / \mathrm{g}$. Polydimethylsiloxanes (P2) (Scheme 1) were given by Chisso Corp. : $\bar{M}_{n} 1260$ (P2a), 4860 (P2b), the values were obtained from analysis of the end hydroxyl group. $N, N^{\prime}, N^{\prime \prime}$-Tris $(\omega$-isocyanatohexyl) isocyanate supplied by Nippon Polyurethane Co. as a polyisocyanate crosslinking agent (Coronate HX) was used as received. Tolylene 2,4-diisocyanate (TDI) (Kanto Chemical Co., Inc.), di-n-butyltin dilaurate (DBTL) (Tokyo Chemical Industry Co., Ltd.), and solvents were used without further purification.

Synthesis of Isocyanate-Terminated Polydimethylsiloxanes (P3a, P3b)

$\mathrm{P} 2 \mathrm{a}$ or P2b (hydroxyl end group $2 \mathrm{mmol}$ ), TDI (2 mmol), a DBTL solution in toluene $\left(145 \mathrm{~mL}, 2 \times 10^{-4}\right.$ $\mathrm{mmol})$, dehydrated toluene $(2 \mathrm{~mL})$, and a magnetic stir-<smiles>CCOC(CC(C)CC(C)(C)C(C)(C)C)CC(C)(C)CC(C)(C)C</smiles>

$\operatorname{Pl}(\overline{\mathrm{M}} \mathrm{n}=15500)$<smiles>CC(C)(C)OCCCCCCCO</smiles>

$\mathrm{P} 2 \mathrm{a}(\overline{\mathrm{M}} \mathrm{n}=1290)$

$\mathrm{P} 2 \mathrm{~b}(\overline{\mathrm{Mn}}=4860)$

Scheme 1. 
<smiles>Cc1ccc([N+](=O)[O-])cc1[N+](=O)[O-]</smiles><smiles>Cc1ccc(NC(=O)OCCCOCCCC(C)(C)[Si](C)(C)C(C)(C)O[Si](C)(C)C(C)(C)C)cc1[N+](=O)[O-]</smiles>

P3a,b

Scheme 2.

ring bar were placed in a flask equipped with a calcium chloride tube. The mixture was kept at room temperature $\left(23^{\circ} \mathrm{C}\right)$ for $6 \mathrm{~h}$ with stirring to give a toluene solution containing P3a or P3b. The P3 solution containing DBTL was used for grafting reaction.

\section{Synthesis of Graft Polymers (P4a, P4b)}

A toluene solution containing P1 (hydroxyl side groups $2 \mathrm{mmol}$ ), prescribed amount of P3a or P3b (isocyanate end group $0.1-0.4 \mathrm{mmol})$, and DBTL $\left(0.1-0.4 \times 10^{-4}\right.$ $\mathrm{mmol}$ ) was magnetically stirred at room temperature (23 ${ }^{\circ} \mathrm{C}$ ) for $24 \mathrm{~h}$. Grafting ratio was calculated from decrease in the peak of P3 in GPC spectra according to the following equation :

$$
\text { grafting ratio }(\%)=\frac{\text { grafted P3 }}{\text { fed } \mathrm{P} 3} \times 100
$$

Grafted P3 was calculated using a computer on the assumption that the overlapped GPC peak is composed of Gaussian peaks of the polymers.

\section{Preparation of Coatings}

A prescribed amount of Coronate $\mathrm{HX}$ as a crosslinking agent was added to a P4 solution obtained by grafting reaction, in which a small amount of P3 was presented. The molar amounts of isocyanate groups of the crosslinking agent added were adjusted to those of calculated hydroxyl groups left on the P4 chain after completion of the grafting reaction. The solution was cast on a glass plate and the plate was kept in an oven thermostated at $140^{\circ} \mathrm{C}$ for $30 \mathrm{~min}$. The $\mathrm{P} 4$ coating formed on the glass plate was washed with isopropyl alcohol to remove trace amounts of unreacted polydimethylsiloxane.

\section{Measurements}

Gel permeation chromatography (GPC) was performed on a JASCO GPC system composed of PU-980 (HPLC pump), 830-RI (RI detector), and 860-CO (column oven) equipped with a TSK gel column $\left(\mathrm{G} 4000 \mathrm{H}_{\mathrm{HR}}\right)$. After grafting, the reaction solutions were diluted with tetrahydrofuran (THF) as eluent and injected into the GPC system.

Sliding angles for a water drop on surfaces of coatings were measured using a contact angle meter CA-X (Kyowa Interface Science Co., Ltd.) equipped with a tiltable sample stage. A water drop of prescribed volume was deposited on a P 4-coated glass plate initially in a horizontal position and tilted slowly ( 1 degree $\mathrm{s}^{-1}$ ) until the drop started to slide. The tilting angle was defined as the sliding angle $(\alpha)$ for the drop.

ESCA was performed on a SHIMADZU ESCA-1000 electron spectrometer equipped with a $\mathrm{Mg}-K_{\alpha} \mathrm{X}$-ray gun. Coating surfaces were etched by an ion gun : argon, $8 \times$ $10^{-3} \mathrm{~Pa}, 2 \mathrm{kV}, 20 \mathrm{~mA}$.

\section{RESULTS AND DISCUSSION}

Methods for the synthesis of isocyanate-terminated polydimethylsiloxane were investigated and the reaction of P2 with TDI was examined to obtain P3 (Scheme 2) that can be grafted onto a fluoropolymer having hydroxyl side groups. Considerable difference in reactivity of two isocyanate groups of TDI has been reported. The rate constant for the reaction of the group at 4-position with butanol at $40^{\circ} \mathrm{C}$ is 8.1 times as large as that for the group at 2-position. After the group at 4-position reacted, the rate constant for the remained group at 2position decreases to one third of the original value. ${ }^{4}$ It should thus be possible to prepare P3 when the isocyanate group at 4-position reacts predominantly. An isocyanate-terminated poly(methyl methacrylate) (PMMA) has been obtained by reaction of PMMA having a hydroxyl end group with a excess amount of TDI ( 2.5 molar times the hydroxyl group). ${ }^{5}$ The IR spectrum of TDI shows a somewhat wide absorption peak due to isocyanate groups at $2268 \mathrm{~cm}^{-1}$. After reaction of the group at 4-position, the absorption peak changes to a sharp one with absorption mixmum at $2276 \mathrm{~cm}^{-1}$. The expected change in the IR spectrum was not observed after heating an equimolar mixture of P2a and TDI in toluene at $60^{\circ} \mathrm{C}$ for $1 \mathrm{~h}$. Prolonged heating of $6 \mathrm{~h}$ resulted in the expected spectrum change indicating that the reaction had proceeded. GPC indicated that a small amount of polysiloxane with increased molecular weight was present. The formation of such a polysiloxane having larger molecular weight became appreciable with increasing reac- 


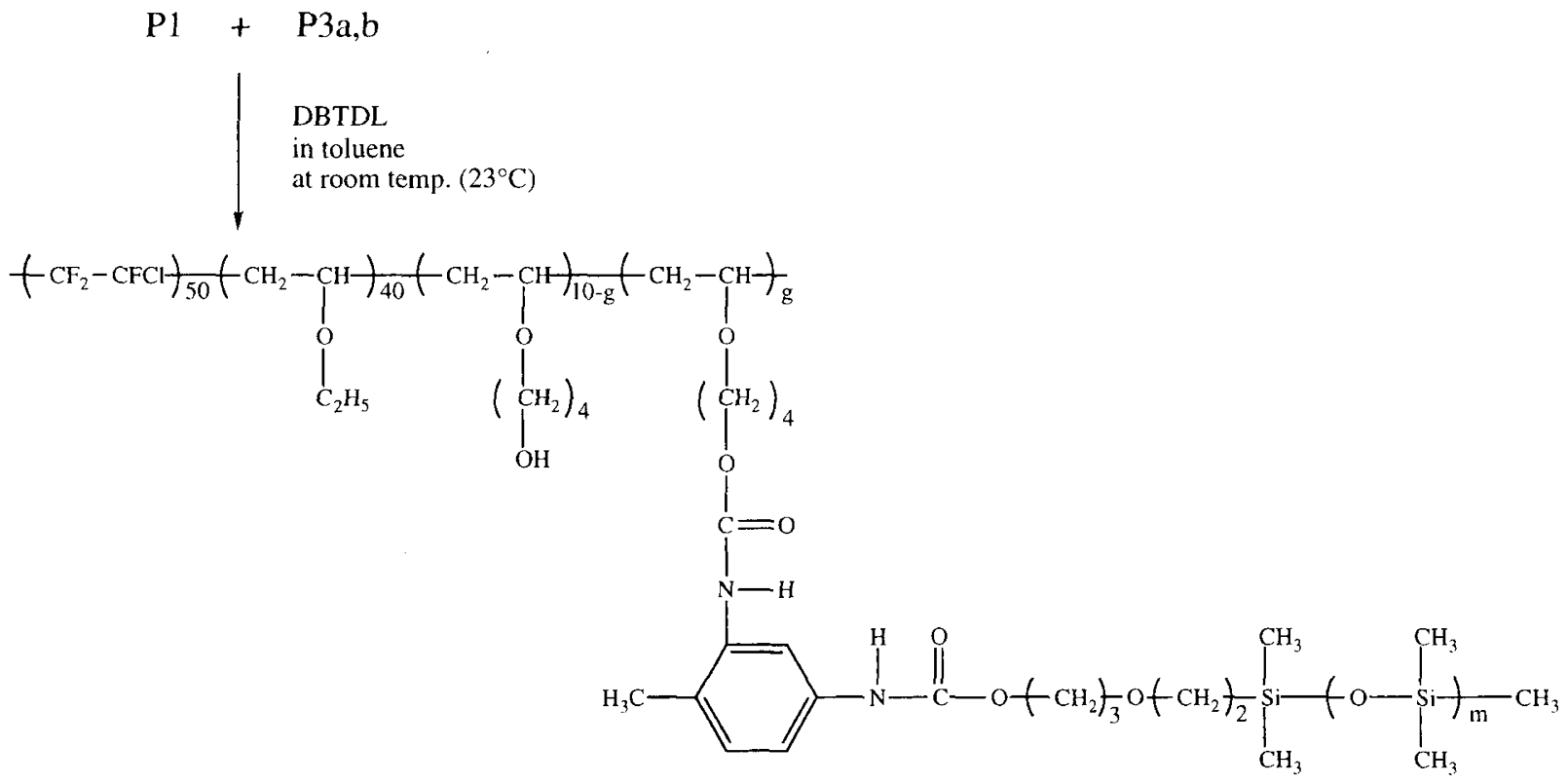

P4a,b

Scheme 3.

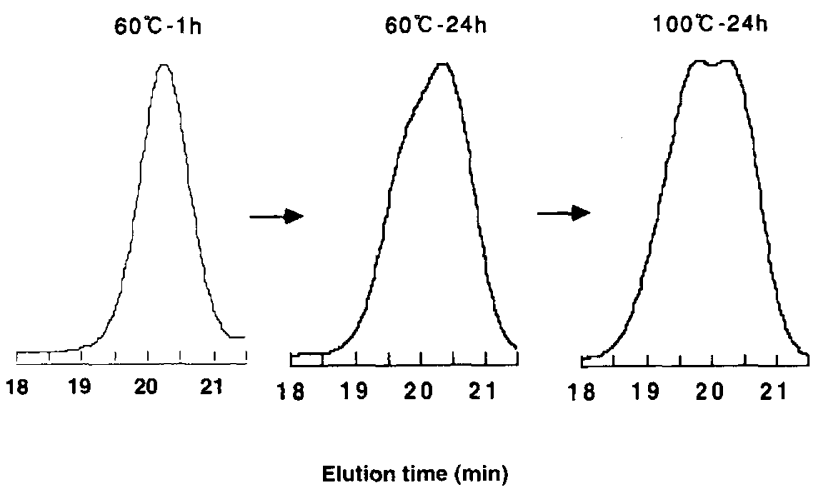

Figure 1. Change in GPC spectrum during reaction of P2a with TDI at higher temperatures in the absence of the DBTL catalyst. Reaction conditions: P2a $2.58 \mathrm{~g}(2 \mathrm{mmol})$, TDI $0.349 \mathrm{~g}(2 \mathrm{mmol})$, toluene $2 \mathrm{~mL}$

tion time, and after reaction at $100^{\circ} \mathrm{C}$ for $24 \mathrm{~h}$, a bimodal GPC spectrum was obtained (Figure 1). These results suggested that the allophanate reaction and/or trimerization of the aryl isocyanate group at the end of formed P3a proceeded slowly at higher temperature.

On using DBTL as a catalyst ( $0.01 \mathrm{~mol} \%$ to TDI), reaction of $\mathrm{P} 2 \mathrm{a}$ with TDI proceeded readily at room temperature $\left(23^{\circ} \mathrm{C}\right)$ and IR spectra of the product showed that the reaction was almost completed within $1 \mathrm{~h}$. In the GPC spectra, no formation of polydimethylsiloxane with increased molecular weight was observed. Thus, the side reaction above is negligible and $\mathrm{P} 3 \mathrm{a}$ is obtained. $\mathrm{P} 3 \mathrm{~b}$ was also synthesized by reaction with P2b of higher molecular weight. Each IR spectrum of P3a and P3b had an absorption peak of the remaining isocyanate group at 2276 $\mathrm{cm}^{-1}$, and GPC indicated unreacted free TDI not to be present. The formation of P3 thus appears almost complete. Reaction solutions of P3's were thus used for grafting without purification. The grafting reaction of P3's onto $\mathrm{P} 1$ is shown in Scheme 3.

A reaction solution for the synthesis of $\mathrm{P} 3$ containing DBTL was mixed with $P 1$ followed by measuring change in the GPC spectrum. As Figure 2 shows, grafting proceeded easily at room temperature $\left(23^{\circ} \mathrm{C}\right)$ because of the catalytic action of DBTL to promote the reaction of isocyanate groups of P3 with hydroxyl groups of P1. Figure 3 shows the effect of reaction temperature on grafting.

To evaluate the hydrophobicity of the polydimethylsiloxane-grafted fluoropolymer, $\mathrm{P} 4$, sliding of water drops on the coating surface was examined. Coatings were prepared by adding a polyisocyanate crosslinking agent (Coronate $\mathrm{HX}$ ) to $\mathrm{P} 4$ solutions obtained after grafting. A small amount of ungrafted P3 was present before coating formation. Free polydimethylsiloxane present on the coating surface acts as a lubricant for water drops. ${ }^{6}$ It was thus removed from the coating after formation by washing with isopropyl alcohol. As a result only trace amounts of polydimethylsiloxane (less than $0.4 \mathrm{wt} \%$ ) were extracted from the coating. This indicates that the grafting was almost completed at the temperature of coating formation $\left(140^{\circ} \mathrm{C}\right)$. Thus, nearly P3 molecules are incorporated in the coating net work.

Contact angles of water on the coatings were determined as 89.6, 91.7, and 99.1 degrees for P1, P4a, and $\mathrm{P} 4 \mathrm{~b}$, respectively, and sliding experiments for water droplets were carried out on coatings prepared from the polymers. The results are shown in Figure 4. Watersliding on the surface of a coating prepared from $\mathrm{P} 4 \mathrm{a}$ that has shorter polydimethylsiloxane side chains was very similar to that on the surface of a coating prepared from ungrafted P1. A small water droplet of $10 \mu \mathrm{l}$ remained even on the vertical plane surface of the coating of either polymer as shown by a cross. However, on the surface of a coating of $\mathrm{P} 4 \mathrm{~b}$ with longer polydimethylsiloxane side chains, a small water droplet of the same volume slid down at a tilt of 30 degrees. The dimethylsi- 


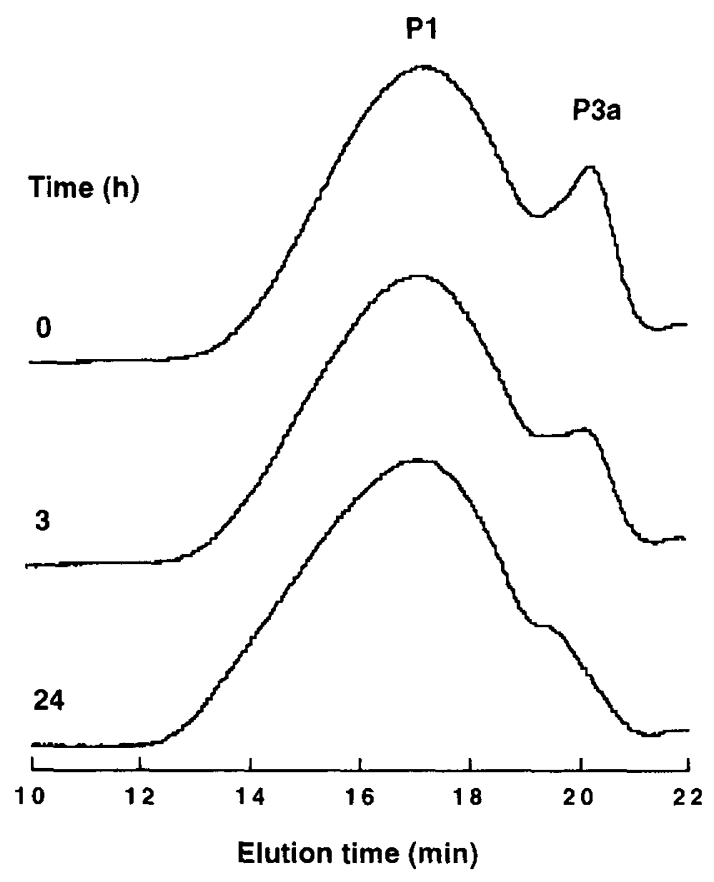

Figure 2. Change in GPC spectrum during the grafting reaction of P3a onto P1. Reaction condition : P1 $1.967 \mathrm{~g}$ (hydroxyl pendant group $2 \mathrm{mmol}$ ), P3a $0.293 \mathrm{~g}$ (isocyanate end group $0.2 \mathrm{mmol}$ ), DBTL $\left(0.2 \times 10^{-4} \mathrm{mmol}\right)$, toluene $2.49 \mathrm{~mL}, 23^{\circ} \mathrm{C}$.

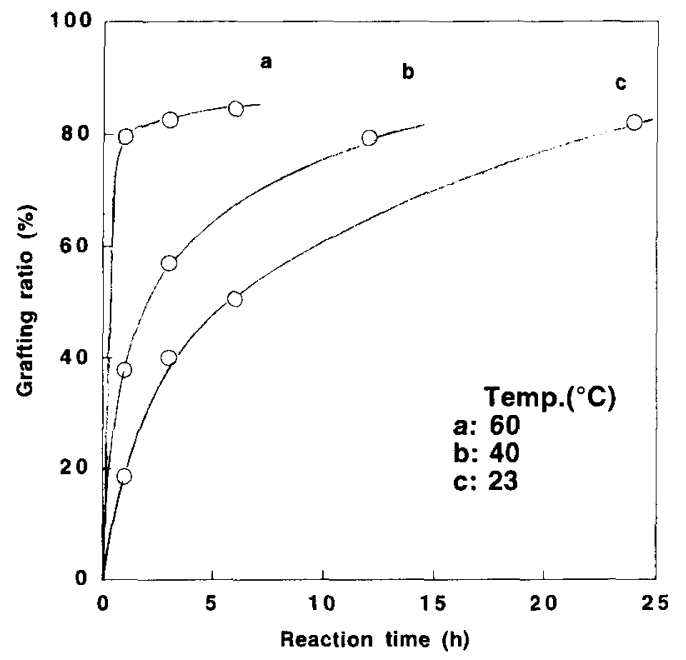

Figure 3. Grafting reaction of $\mathrm{P} 3 \mathrm{a}$ onto $\mathrm{P} 1$ at various temperatures. Reaction conditions: P1 $1.967 \mathrm{~g}$ (hydroxyl pendant group 2 $\mathrm{mmol})$, P3a $0.293 \mathrm{~g}$ (isocyanate end group $0.2 \mathrm{mmol})$, DBTL $(0.2 \times$ $10^{-4} \mathrm{mmol}$ ), toluene $2.49 \mathrm{~mL}$.

loxane unit content of P4b was approximately adjusted to that of P4a. Polymeric materials for hydrophobic coating, on which water droplets easily slide, must thus have longer polydimethylsiloxane side chains.

Elemental analysis of the P4b coating surface showing excellent water-sliding was performed by ESCA (Figure 5 ). The atomic ratio (in number) of silicone on the surface of a P4b coating was markedly greater than that of the polymer. The polydimethylsiloxane chains thus move to the surface during formation of the coating to decrease surface energy, because surface energy of the polydimethylsiloxane is smaller than that of the fluoro-

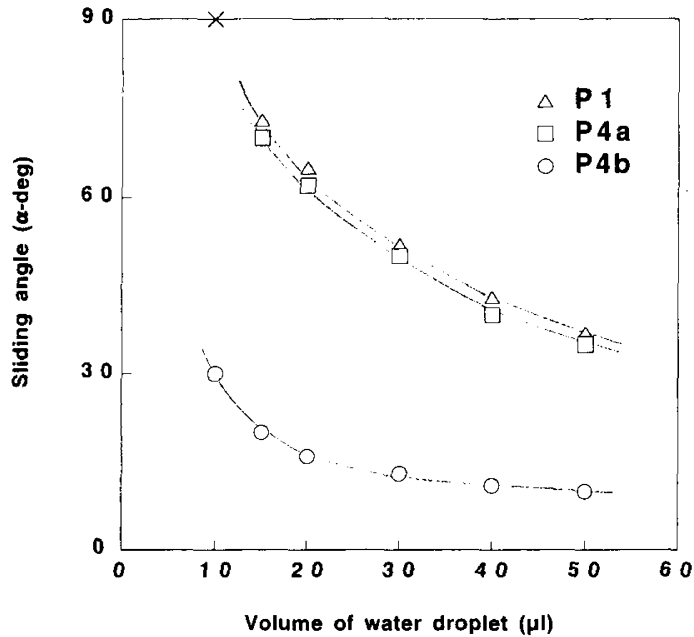

Figure 4. Sliding angles of water droplets on the surfaces of P1 and $\mathrm{P} 4$ coatings. $\mathrm{P} 4 \mathrm{a}$ was obtained by grafting $0.586 \mathrm{~g}$ of $\mathrm{P} 3 \mathrm{a}$ (isocyanate end group $0.4 \mathrm{mmol}$ ) onto $1.967 \mathrm{~g}$ of $\mathrm{P} 1$ (hydroxyl pendant group $2 \mathrm{mmol}$ ) and $\mathrm{P} 4 \mathrm{~b}$ by grafting $0.504 \mathrm{~g}$ of $\mathrm{P} 3 \mathrm{~b}$ (isocyanate end group $0.1 \mathrm{mmol}$ ) onto $1.967 \mathrm{~g}$ of P1 (hydroxyl pendant group 2 $\mathrm{mmol}$ ).

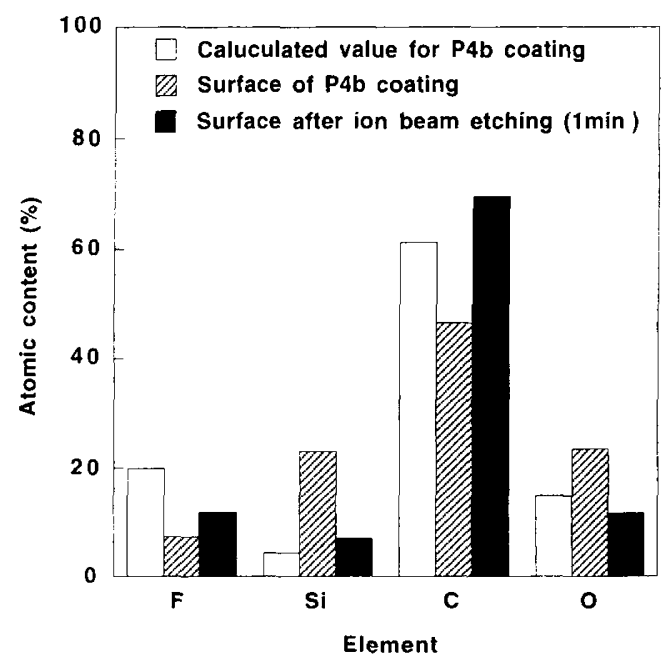

Figure 5. Elemental analysis of the surface of a P4b coating by ESCA. P4b coating was prepared in the same way as in Figure 4.

polymer used in this study. ${ }^{7}$ The silicon content on the coating surface decreased to the calculated value for $\mathrm{P} 4 \mathrm{~b}$ after ion beam etching of the surface. Sliding of liquid drops on a substrate inevitably depends on the roughness of the surface. An AFM observation of P4b coating showed height corrugation of $1-6 \mathrm{~nm}$. Thus the surface of the coating is remarkably smooth.

The detailed mechanism for sliding of water drops on the surface consisting of polydimethylsiloxane is unclear. Murase et al. computed the interaction between water molecules and a solid surface composed of siloxane units and fluorinated alkylene moieties using a molecular orbital calculation and discussed sliding of a water drop on a surface of such a hybrid material. ${ }^{2}$ Kawai defined a "fall angle" of a water drop on various inclined substrates and related it to polar and dispersion components of surface energy. ${ }^{8}$ Extrand et al. investigated the retentive force for a drop of water or ethylene glycol on 
tilted plane surfaces of solid polymers and silicon wafers and discussed the force on the basis of advancing and receding contact angles of the sliding drops. ${ }^{9}$ Carre et al. reported theoretical analysis of the motion of a water drop on a plane surface of glass treated with a hydrophobic material. ${ }^{10}$

Tezuka etal. synthesized many hydrophilic polysiloxane-grafted copolymers such as polyurethane/ polysiloxane and polyvinyl alcohol/polysiloxane to examine their environmental response and application for medical uses. ${ }^{11}$

Although no theory for sliding of a water drop on surfaces of polymer coatings has been elaborated, polymeric materials for coatings on which small water droplets slide easily are widely expected to be developed. The graft polymer obtained in our investigation may be used for this purpose.

\section{REFERENCES}

1. A. E. Mark and K. J. Wynne, Polym. Prepr., Am. Chem. Soc., Div. Polym. Chem., 39, 806 (1998).

2. H. Murase, K. Nanishi, H. Kogure, T. Fujibayashi, K. Tamura, and N. Haruta, J. Appl. Polym. Sci., 54, 2051 (1994).

3. M. Takeishi, I. Narisawa, H. Suzuki, and H. Murase, 23rd Symposium for Composite Materials, Yonezawa, Japan, Prepr., 2(1998) ; J. Appl. Polym. Sci., in press.

4. M. Sumi and S. Kazama, Polym. Prepr., Jpn., 13, 594 (1964).

5. B. Boutevin, J-M. Lusinchi, Y. Rietrasanta, and J-J. Robin, Eur. Polym. J, 30,615 (1994).

6. H. Suzuki and M. Takeishi, unpublished data.

7. H. Suzuki, T. Kobayashi, S. Sasaki, T. Kuriyama, and M. Takeishi, J. Adhes. Soc. Jpn., in press.

8. A. Kawai, J. Adhes. Soc. Jpn., 34, 191 (1998).

9. C. W. Extrand and Y. Kumagi, J. Colloid Interface Sci., 170, 515 (1995).

10. A. Carre and M. E. Shanahan, J. Adhesion., 49, 177 (1995).

11. For example, Y. Tezuka, H. Kazama, T. Ono, and K. Imai, Kobunshi Ronbunshu, 48, 227 (1991) 